\title{
Factors Influencing Perception of Labor Pain among Parturient Women at Tribhuvan University Teaching Hospital
}

\author{
Shrestha I, ${ }^{1}$ Pradhan N, ${ }^{2}$ Sharma J ${ }^{2}$ \\ ${ }^{1}$ Department of Obstetrics and Gynaecology, Civil Service Hospital,Kathmandu, Nepal, \\ ${ }^{2}$ Department of Obstetrics and Gynaecology, Tribhuvan University Teaching Hospital, Kathmandu, Nepal.
}

\begin{abstract}
Aims: This study was done to understand the severity of labor pain in parturients of Kathmandu and to determine factors affecting it.
Methods: A descriptive study was conducted in Tribhuvan University Teaching Hospital (TUTH), Kathmandu, Nepal where 300 term parturientsin active labor (cervical dilatation of $3-5 \mathrm{~cm}$ with three uterine contractions in 10 minutes each lasting for $\geq 30$ seconds) were analysed for socio-demographic data, clinical profile and pain assessment.Visual analog scale was used for pain assessment.

Results: The intensity of labor pain was graded as severe by $32 \%$, moderateby $57 \%$ and mild by $11 \%$ of parturients.Almost half ofthe parturients in the age group of $\leq 19$ years described labor pain as severe as compared to women between 20-34years (30.4\%) and $\geq 35$ years $(20 \%)$. Among the nulliparous parturients, $37 \%$ described it as severe compared to only $20.7 \%$ in $\geq$ Paral.In those with $\geq$ higher secondary leveleducation, $35.9 \%$ described labor pain as severe as compared to those women who had education of $\leq$ primary level $(26.9 \%)$ and upto secondary level (27.1\%). Labor pain was seen to be more severe in advanced labor withmore than half describingit as severe when the cervix was dilated to $5 \mathrm{~cm}$, as compared to only $25.9 \%$ and $29.4 \%$ of the parturients at 3 and $4 \mathrm{~cm}$ cervical dilatation respectively.
\end{abstract}

Conclusions: This study concluded that the labor pain was moderate to severe for majority of the parturients.Adolescents, nullipara, patients with higher education and those in advanced laborwere more likely to perceive labor pain of higher intensity.

Keywords: advanced labor, laborpain, visual analog scale.

\section{INTRODUCTION}

Labor is considered to be one of the most painful experiences in life. ${ }^{1}$ Labor pain is an inevitable and intricate part of the childbirth. ${ }^{2}$ The intensity of the pain experienced during labor affects maternal psychology, labor progress and fetal well-being.

Physiologicalfactors, suchasuterinecontractionsandcervical dilatation though essential parts of labor, are the major contributors to labor pain. Psychological factors, such as stress, anxiety, fear, sense of loss of control and sense of abandonment also contribute to it. ${ }^{2}$ There is a wide spectrum of factors which may influence labor pain including personal, physical and medical characteristics. ${ }^{1}$
It is seen that $68.3 \%$ of women described labor pain as severe and $>86 \%$ of the women would want the pain to be relieved. ${ }^{3}$ Understanding the patient's suffering and ensuring safelabor with minimal pain is one of the basic principles of modern obstetrics. ${ }^{1-3}$ So this study was conducted to understand the severity of labor pain in parturients of Kathmandu and to determine factors affecting it.

\section{METHODS}

This was a descriptive study conducted at labor room of Obstetrics and Gynecology Department of Tribhuvan

\section{CORRESPONDENCE}

Dr Isha Shrestha

Department of Obstetrics and Gynecology, Civil Service Hospital, Kathmandu, Nepal. Email: dr.ishashrestha@gmail.com Phone: +977- 9851153065
The papers in this journal are published under the terms of the Creative Commons Attribution License. Users are allowed to read, download, copy, distribute, print, search, or link to the full texts of the articles in this journal without asking prior permission from the publisher or the author. 
University Teaching Hospital (TUTH), from April 2008 to April 2009. The study was conducted in 300 women with singleton pregnancy at term (37-42 weeks) with vertex presentation admitted in active labor (cervical dilatation of $3-5 \mathrm{~cm}$ with 3 uterine contractions in 10 minutes each lasting for 30 seconds or more) with expectancy for uncomplicated vaginal delivery. Parturients with previous uterine scars, intrauterine fetal demise or congenital anomaly of fetus, maternal medical diseases or chronic drug use, conditions requiring immediate delivery or those who did not give consent were excluded from the study.

The patients' socio-demographic data and clinical profile were entered in the preformed questionnaire. Visual analog scale (VAS) was used for the pain assessment. VAS is a psychometric response scale for quantifying pain and it can be used in questionnaires and is a $10 \mathrm{~cm}$ long horizontal line bounded by "no pain" on the left and "worst pain possible" on the right.

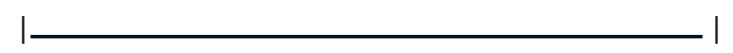

No pain

Worst pain possible

The pain assessment was done immediately after a contraction by asking the woman to mark on this line where she felt the intensity of her pain lies. The patient's mark on the line represented her perception of pain at her current state. The VAS score was determined by measuring in centimetres from the left hand end of the line ('no pain') to the point that the patient marked. The severity of labor pain was graded as mild when the VAS score was 0.1-3.9 and as moderate when the score was 4-6.9. When the VAS score was 7-10 it was graded as severe. Data were analysed using Statistical Package for Social Studies (SPSS) version 13.

\section{RESULTS}

During the study period 300 patients who fulfilled the inclusion criteria and gave consent to participate in the study were enrolled. The minimum age of the women was 16 and the maximum was 37 . The mean age was 24 with a standard deviation of 4.3 years. Majority (46.3\%) were between 20 to 24 years of age.

Fifty-nine percent of the parturients were of Indo-Aryan ethnicity who comprised of Brahmin, Chhetri, Tharu, Rajbansi, Darai, Kumal and Majhi. Forty-one percent were of Tibeto-Burman ethnicity who were Newar, Gurung, Magar, Rai, Limbu, Sherpa, Thakali, Tamang, Jirel and Thami. Majority (90.3\%) were Hindus. Seventy-four percent of the women were housewives. Among the 26 women with less than or equal to primary education (education upto class three) 12 were illiterate. Majority (55.7\%) had education of higher secondary or above (education of intermediate level and above). The distribution of women according to age, ethnicity, religion, education and occupation are shown in Table 1.

Table 1. Distribution of the women according to age, ethnicity, religion, education and occupation $(n=300)$.

\begin{tabular}{|c|c|c|}
\hline Age in years & Number & Percentage \\
\hline$\leq 19$ & 35 & 11.7 \\
\hline $20-24$ & 139 & 46.3 \\
\hline $25-29$ & 90 & 30 \\
\hline $30-34$ & 31 & 10.3 \\
\hline$\geq 35$ & 5 & 1.7 \\
\hline \multicolumn{3}{|l|}{ Ethnicity } \\
\hline Indo-Aryan & 178 & 59.3 \\
\hline Tibeto-Burman & 122 & 40.7 \\
\hline \multicolumn{3}{|l|}{ Religion } \\
\hline Hindu & 271 & 90.3 \\
\hline Buddhist & 27 & 9.0 \\
\hline Muslim & 2 & 0.7 \\
\hline \multicolumn{3}{|l|}{ Education } \\
\hline$\leq$ Primary & 26 & 8.7 \\
\hline $\begin{array}{l}\text { Lower } \\
\text { Secondary } \\
\text { Secondary }\end{array}$ & 107 & 35.7 \\
\hline $\begin{array}{l}\geq \text { Higher } \\
\text { Secondary }\end{array}$ & 167 & 55.7 \\
\hline \multicolumn{3}{|l|}{ Occupation } \\
\hline Housewife & 223 & 74.3 \\
\hline Service & 24 & 8.0 \\
\hline Student & 21 & 7.0 \\
\hline Professional & 18 & 6.0 \\
\hline Business & 14 & 4.7 \\
\hline
\end{tabular}

Most $(69.3 \%)$ were nullipara. Almost $50 \%$ had cervical dilatation of $3 \mathrm{~cm}$ at the time of enrollment and the mean cervical dilatation of the women was $3.68 \mathrm{~cm} \pm 0.73$. Most of the parturients $(31 \%)$ were in the gestational age of 39 $39+6$, closely followed by $25.3 \%$ ingestational age of $38-$ $38^{+6}$ and $22.6 \%$ in gestational age of $40-40^{+6}$ (Table 2 ). 
Table 2. Distribution of the women according to parity, cervical dilatation and gestational age $(n=300)$.

\begin{tabular}{lll}
\hline Characteristics & Number & Percentage \\
\hline Para & 208 & 69.3 \\
0 & 72 & 24.0 \\
1 & 16 & 5.3 \\
2 & 4 & 1.3 \\
$\geq 3$ & & \\
Cervical dilatation & 143 & 47.7 \\
$3 \mathrm{~cm}$ & 109 & 36.3 \\
$4 \mathrm{~cm}$ & 48 & 16.0 \\
$5 \mathrm{~cm}$ & & \\
Gestational age & 51 & 17.0 \\
$37-37^{+6}$ & 76 & 25.3 \\
$38-38^{+6}$ & 93 & 31.0 \\
$39-39^{+6}$ & 68 & 22.6 \\
$40-40^{+6}$ & 12 & 4.0 \\
$41-41^{+6}$ & & \\
\hline
\end{tabular}

For majority (57\%), the intensity of labor pain was moderate, $32 \%$ had as severe and only $11 \%$ described it as mild (Figure 1). Pain perception was compared among women with various socio-demographic factors and obstetric factors (Table 3).

Table 3. Pain score according to socio-demographic and obstetric profile of the women $(n=300)$.

\begin{tabular}{llll}
\hline \multicolumn{3}{c}{ Baseline pain score } \\
\hline Age in years & Mild & Moderate & Severe \\
$\leq 19$ & $2(5.7)$ & $17(48.6)$ & $16(45.7)$ \\
$20-34$ & $31(11.9)$ & $150(57.7)$ & $79(30.4)$ \\
$\geq 35$ & 0 & $4(80.0)$ & $1(20.0)$ \\
Parity & Mild & Moderate & Severe \\
Nullipara & $21(10.1)$ & $110(52.9)$ & $77(37.0)$ \\
$\geq$ P1 & $12(13.0)$ & $61(66.3)$ & $19(20.7)$ \\
Literacy & Mild & Moderate & Severe \\
$\leq$ Primary & $3(11.5)$ & $16(61.5)$ & $7(26.9)$ \\
Secondary & $9(8.4)$ & $69(64.5)$ & $29(27.1)$ \\
$\geq$ Higher & $21(12.6)$ & $86(51.5)$ & $60(35.9)$ \\
Secondary & & & \\
Cervical & Mild & Moderate & Severe \\
dilatation & & & \\
3 cm & $27(18.9)$ & $79(55.2)$ & $37(25.9)$ \\
4 cm & $5(4.6)$ & $72(66.1)$ & $32(29.4)$ \\
5 cm & $1(2.1)$ & $20(41.7)$ & $27(56.3)$ \\
\hline Figures in the parentheses indicate the percentage
\end{tabular}

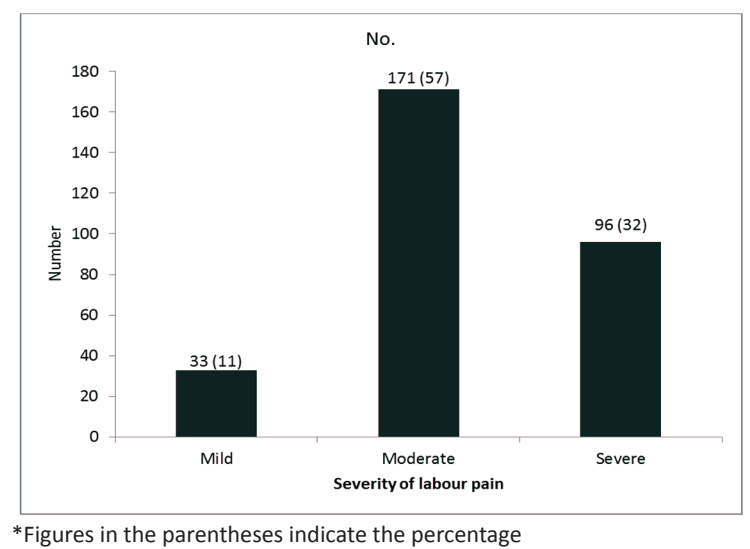

*Figures in the parentheses indicate the percentage

Figure 1. Pain score $(n=300)$.

Adolescent girls were more likely to perceive labor pain of higher intensity. Among the parturients in the age group of $\leq 19$ years almost half of them $(45.7 \%)$ described labor pain as severe as compared to women who were between 20 to 34 years $(30.4 \%)$ and $\geq 35$ years $(20 \%)$.

Similarly nulliparous parturients described the labor pain to be more severe. Among the 208 nulliparous parturients, $37 \%$ described it as severe, whereas only $20.7 \%$ of the parturients who were para 1 and above described it as severe.

Patients with higher education seemed to perceive labor pain as more severe. Out of 167 women who had education upto higher secondary level or more, $35.9 \%$ described labor pain as severe as compared to those women who had education upto primary level or less (26.9\%) and upto secondary level $(27.1 \%)$

Labor pain was more severe when the patient presented in advanced labor. So when the cervix was dilated to $5 \mathrm{~cm}$, more than half described labor pain as severe as compared to only $25.9 \%$ and $29.4 \%$ of the parturients who presented at 3 and $4 \mathrm{~cm}$ cervical dilatation respectively.

\section{DISCUSSION}

In this study, only $11 \%$ of the parturients described the labor pain as mild. For majority (57\%), the intensity of labor pain was moderate and for $32 \%$ it was severe. This finding is congruent with findings of other studies. In a study by Rooth et $\mathrm{al}^{4} \mathbf{6 8 . 3} \%$ of women described labor pain as being severe and more than $86 \%$ of them would want the pain to be relieved. Melzack et $\mathrm{al}^{5}$ also noted that only patients from the amputation of a digit reported greater pain on average than women in labor. Similarly, high levels of pain intensity during labor was reported in 100 Jordanian parturients with a mean Numeric Pain Intensity Scale of 8.82 .2 
Labor pain was found to be more severe in younger age. More number of adolescent parturients described the labor pain to be severe as compared to those above 20. This finding was consistent with the findings of Melzack et $\mathrm{al}^{6}$ who also found a trend towards less labor pain experienced by older women compared to younger. A multicentre study in six hospitals in five European countries ${ }^{7}$ and a study by Sheiner et $\mathrm{al}^{8}$ in 447 women have also confirmed that pain perception decreased with advancing age.This may be due to a higher pain threshold with increased age which was confirmed by some studies..$^{9,10}$ But other studies could not find such an association. Age as a predictor of higher pain scores was not shown in the study done by Klostergaard et $\mathrm{al}^{1}$ in 139 primipara or by Ohel et al ${ }^{11}$ in 40 parturients which may be because of small sample size.

In this study, more patients with education of higher secondary or above (35.9\%) perceived labor pain as severe as compared to those with education of primary or below primary level (26.9\%) and lower secondary to secondary level (27.1\%). A study by Olayemi O et al $^{12}$ in 765 parturients using a questionnaire with the Box Numerical Scale (BNS) to assess pain within 48 hours of delivery also noted that the pain scores were lowest among those with no formal education. Multivariate analysis revealed educational attainment as a significant predictor of BNS. The reason behind higher pain score among those with higher education may be due to easy life styles of those with higher education thus not being able to tolerate much pain.

The intensity of pain perception during labor appeared to be different in nulliparous and multiparous women. In this study more of the nulliparous parturients (37\%) described the labor pain to be more severe as compared to only $20.7 \%$ of the parturients who were Para1 and above. Though the parity was not seen to affect the intensity of pain in the studies done by Aushaikha et al ${ }^{12}$, Shapira et $\mathrm{al}^{13}$; another study found that $25 \%$ of nulliparous women ( $n=87$ ) compared to $9 \%$ of parous women $(n=54)$ described their labor pain as horrible or excruciating. ${ }^{14}$ The findings of other studies indicated that during early labor (before $5 \mathrm{~cm}$ ), nulliparous women on average experience greater sensory pain than multiparous women. ${ }^{8,15-20}$ While as labor progressed, these differences were less pronounced, except for a possible increase in pain intensity during the pelvic phase of labor (deceleration and second stage) in multiparous women. ${ }^{16,19,20}$ The affective component of pain which refers to the unpleasantness or emotional distress seems to be greater throughout the first stage of labor for nulliparous as compared to multiparous parturients, but it tends to decrease in both groups during the second stage. ${ }^{16,18,21}$ This may be because the nulliparous women experiencing labor pain for the first time go through greater emotional distress as compared to multiparous women.
Labor pain was seen to be more severe when the patient presented in advanced labor. So when the cervix was dilated to $5 \mathrm{~cm}$, more than half $(56.3 \%)$ described labor as severe as compared to only $25.9 \%$ and $29.4 \%$ of the parturients who presented at 3 and $4 \mathrm{~cm}$ cervical dilatation respectively. This finding is consistent with Present Pain Intensity data from a mixed parity sample of 78 parturients which showedthat before $5 \mathrm{~cm}$ of dilatation, only $24.4 \%$ described their pain as horrible or excruciating, whereas after $5 \mathrm{~cm}$ of dilatation, $46.2 \%$ did so. ${ }^{22}$ The pain during first stage of labor is due to the distention of cervix and lower uterine segment which explains the increase in pain severity as the cervical dilatation increases.

\section{CONCLUSIONS}

This study concluded that the labor pain was moderate to severe for majority of the parturients.Adolescent girls, nulliparous parturients, patients with higher education and those in advanced laborwere more likely to perceive labor pain of higher intensity.

\section{REFERENCES}

1. Ohel I, Walfisch A, Shitenberg D, Sheiner E, Hallak M. A rise in painthreshold during labor: a prospective clinical trial. Pain. 2007;132 Suppl 1:S104-8.

2. Abushaikha L, Oweis A. Labor pain experience and intensity: a Jordanianperspective. Int J Nurs Pract. 2005;11(1):33-8.

3. Nagaria T, Acharya J. Pain relief in labor: tramadol versus pentazocine.J Obstet Gynaecol India. 2006;56(5):406-9.

4. Rooth G, McBride R, Ivy BJ. Fetal and maternal pH measurements:a basis for common normal values. Acta Obstet Gynecol Scand. 1973;52(1):47-50.

5. Melzack R. The myth of painless childbirth (the John J. Bonica lecture). Pain. 1984;19(4):321-37.

6. Melzack R, Kinch R, Dobkin P, Lebrun M, Taenzer P. Severity of laborpain: influence of physical as well as psychologic variables. Can Med Assoc J. 1984;130(5):579-84.

7. Capogna G, Alahuhtat S, Celleno D, De Vlieger H, Moreira J, Morgan B, et al. Maternal expectations and experiences of labor pain and analgesia: amulticentre study of nulliparous women. Int J Obstet Anesth. 1996;5(4):229-35.

8. Sheiner E, Sheiner EK, Shoham-Vardi I. The relationship between parity andlabor pain. Int J Gynaecol Obstet. 1998;63(3):287-8.

9. Tucker MA, Andrew MF, Ogle SJ, Davidson JG. Age associated change inpain threshold measured by transcutaneous neuronal electric stimulation. Age Ageing. 1989; 18(4):241-6. 
10. Washington LL, Gibson SJ, Helme RD. Age-related differences in theendogenous analgesic response to repeated cold water immersion in human volunteers. Pain. 2000;89(1):89-96.

11. Klostergaard KM, Terp MR, Poulsen C, Agger AO, Rasmussen KL. Laborpain in relation to fetal weight in primiparae. EurJ Obstet Gynecol Reprod Biol. 2001;99(2)195-8.

12. Olayemi O, Aimakhu CO, Akinyemi OA. The influence of westernization on pain perception in labor among parturients at the university college hospital Ibadan. J Obstet Gynaecol. 2006;26(4):329-31.

13. Shapira SC, Magora F, Chrubasik S, Feigin E, Vatine JJ, Weinstein D. Assessment of pain threshold and pain tolerance in women in labor and inearly post-partum period by pressure algometry. Eur J Anaesthesiol. 1995;12(5):495-9.

14. Fairlie FM, Marshall L, Walker JJ, Elbourne D. Intramuscular opioids formaternal pain relief in labor: a randomised controlled trial comparing pethidine with diamorphine. $\mathrm{Br} \mathrm{J}$ Obstet Gynaecol. 1999;106(11):1181-7.

15. Brown ST, Campbell D, Kurtz A. Characteristics of labor pain at two stages of cervical dilation. Pain. 1989;38(3):289-95.
16. Lowe NK. Differences in first and second stage labor pain betweenn ulliparous and multiparous women. J Psychosom Obstet Gynaecol. 1992;13:243-53.

17. Melzack R, Taenzer P, Feldman P, Kinch RA. Labor is still painful after prepared childbirth training. Can Med Assoc J. 1981;125(4):357-63.

18. Gaston-Johansson G, Fridh G, Turner-Norvell K. Progression of labor pain in nulliparas and multiparas. Nurs Res. 1988;37(2):86-90.

19. Lowe NK. Parity and pain during parturition. J Obstet Gynecol Neonatal Nurs.1987;16(5):340-6.

20. Ranta $P$, Jouppila $P$, Jouppila R. The intensity of labor pain in grand multiparas. Acta Obstet Gynecol Scand. 1996;75(3):250-4

21. Price DD, Harkins SW, Baker C. Sensory-affective relationships among different types of clinical and experimental pain. Pain. 1987;28(3):297-307.

22. Kainz C, Joura E, Obwegeser R, Plockinger B, Gruber W. Effectiveness and tolerance of tramadol with or without an antiemetic and pethidine in obstetric analgesia (translation) Z Geburtshilfe Perinatol. 1992;196(2):78-82. 